\title{
CCR9 antagonism: potential in the treatment of Inflammatory Bowel Disease
}

This article was published in the following Dove Press journal:

Clinical and Experimental Gastroenterology

7 April 2015

Number of times this article has been viewed

\section{Emily Wendt \\ Satish Keshav \\ Translational Gastroenterology Unit, Nuffield Department of Medicine, John Radcliffe Hospital, Oxford, UK}

Correspondence: Satish Keshav

Gastroenterology Unit, Nuffield Department of Medicine, Level 5, John Radcliffe Hospital, Headley Way, Oxford, OX3 9DU, UK

$\mathrm{Tel}+44 \quad 1865228759$

Fax +441865228763

Email satish.keshav@ndm.ox.ac.uk
Abstract: Inflammatory Bowel Disease (IBD), mainly comprising Crohn's disease (CD) and ulcerative colitis (UC), is a chronic condition that primarily affects the intestine and is characterized by leukocytic infiltration. Blocking the migration of leukocytes from the circulation is therefore a reasonable therapeutic goal. Recent clinical trials using this approach have shown promise, with the monoclonal antibody to $\alpha_{4} \beta_{7}$ integrin, vedolizumab, and previously with the monoclonal antibody to the $\alpha_{4}$ subunit, natalizumab. Directly targeting the subset of $\alpha_{4} \beta_{7}$ expressing cells that co-express CC chemokine receptor 9 (CCR9), using the orally administered antagonist, CCX282-B, also known as vercirnon, has also been evaluated in Phase II and III trials that have produced mixed results. Although CCX282-B showed efficacy in inducing response in active CD in early studies, this was not confirmed in a Phase III study. CCX282-B was also more effective than placebo in maintaining remission, and this result has yet to be confirmed in Phase III. The efficacy of blocking CCR9 in UC, where vedolizumab was effective, has not been tested. The prospect of targeting CCR9 in IBD remains attractive. Much of the local accumulation of inflammatory cells in the intestine arises from migration rather than local proliferation and genetic and pharmacological targeting of CCR9 or its ligand in preclinical models that mimic $\mathrm{UC}$ and $\mathrm{CD}$ ameliorate inflammation in some cases. Furthermore, binding of chemokine ligands to receptor is a critical step in activating integrin binding, so there is a potential for synergistic action between integrin and chemokine antagonists. CCR9 is expressed on a smaller proportion of circulating cells than $\alpha_{4} \beta_{7}$ integrin, which may offer greater specificity of effect, particularly in long term use. Furthermore, while $\alpha_{4} \beta_{7}$ is widely expressed on T and B cell subsets, CCR9 is mainly expressed on effector memory Th1 cells. Indications for the use of intestine-specific integrin and chemokine receptor targeting may also extend beyond IBD, to include, for example, postoperative ileus, and primary sclerosing cholangitis.

Keywords: Crohn's disease, ulcerative colitis, CCL25, CCX282-B, Traficet-EN, GSK10605786, CC chemokine receptor 9

\section{Introduction}

Inflammatory Bowel Disease (IBD) is a chronic condition comprising mainly two subgroups: Crohn's disease (CD) and ulcerative colitis (UC), distinguished by clinical, endoscopic, and pathological features that overlap to some extent. Approximately 2.2 million Europeans and 1.4 million North Americans are affected by IBD, with rising incidence and prevalence in Westernized nations. ${ }^{1,2}$ IBD occurs equally in both sexes, and the incidence is highest in the second to fourth decades of life, affecting people at the prime of their economic and reproductive lives. ${ }^{2,3}$ IBD is characterized by leukocytic infiltration in the intestinal mucosa; chemokine receptors and their 
cognate chemokine ligands contribute to inflammation by mediating the directional migration of cells, in for instance, extravasation of cells from the circulation into tissues. ${ }^{4,5}$ Intestine specific homing molecules such as $\mathrm{CC}$ chemokine receptor 9 (CCR9) and its ligand, CC ligand 25 (CCL25) are targets amenable to the development of blocking drugs. In this review, we highlight pertinent differences between $\mathrm{CD}$ and UC, review what is known about CCR9 in the context of homeostatic and inflammatory recruitment to the intestine, and discuss preclinical and clinical data on the use of CCR9 antagonists in IBD.

\section{Pathology and immunophenotype in CD and UC}

CD can affect any part of the gastrointestinal tract, from mouth to anus, and in the majority of cases $(-80 \%)$ includes inflammation of the distal small intestine; roughly $60 \%$ of patients with $\mathrm{CD}$ will also have inflammation of the colon. ${ }^{6}$ Intestinal lesions manifest in patches, with inflamed tissue adjacent to healthy or quiescent mucosa. $\mathrm{CD}$ is also associated with granulomas, strictures and fistulas, features that are not typically present in UC. ${ }^{7,8}$ Histological evaluation reveals an accumulation of leukocytes in the lamina propria (LP), and inflammatory cells penetrating deep into the submucosal layers. Prolonged or extensive inflammation changes the intestinal architecture, expanding the LP and causing thickened, distorted villi.

Although infiltrating cells are heterogeneous, and the cell population promoting inflammation is still debated, $\mathrm{CD}$ shows many features of a Th1 type inflammatory condition. ${ }^{3,9-11}$ This is on the basis of work since the early 1990s, demonstrating that $\mathrm{CD}$ lesions have elevated expression of Th1 associated cytokines. ${ }^{11-15}$ Th1 cells are a subgroup of $\mathrm{CD} 4^{+} \mathrm{T}$ helper cells that primarily secrete interferon (IFN)- $\gamma$, and are polarized toward a Th1 phenotype by the action of interleukin (IL)-12 through the transcription factor T-bet. ${ }^{16}$ Th1 cells have a critical role in host defense against intracellular pathogens including viruses and bacteria, although an exacerbated Th1 response is deleterious, as demonstrated by the Th1 response caused by Mycobacterium tuberculosis. Indeed, pathologically, $\mathrm{CD}$ can be hard to distinguish from intestinal tuberculosis.

A Th1 rich cytokine environment is not a general feature of IBD; in inflamed lesions in UC, undetectable or low levels of IFN- $\gamma$ have been reported. ${ }^{10,13} \mathrm{Th} 2$ associated cytokines, including IL-5 and IL-13 are often over-expressed..$^{10,17,18} \mathrm{Th} 2$ cells are $\mathrm{CD} 4^{+} \mathrm{T}$ helper cells that have a role in host defense against extracellular pathogens including parasites, and are regulated by the transcription factor GATA3. ${ }^{19}$ They also play an important role in humoral immunity; IL-5 and IL-13 stimulate B cell class switching and antibody production. In UC, inflammation is confined to the colon, presenting as superficial and continuous ulceration, usually involving the rectum (proctitis) and extending proximally in the colon for a variable distance. The majority of patients $(\sim 80 \%)$ have limited, distal colitis or proctitis, and $\sim 20 \%$ have inflammation of the entire colon, or pan-colitis. ${ }^{6}$

The Th17 pathway is implicated in both CD and UC. Th17 polarized $\mathrm{CD} 4^{+} \mathrm{T}$ helper cells produce IL-17A, IL-17F, and IL-22, and are regulated by the transcription factor ROR $\gamma .{ }^{20}$ IL-17 is a neutrophil chemo-attractant, critical in host defense against extracellular infections and potentially deleterious when excessively produced. ${ }^{21}$ Genome-wide association studies implicate polymorphisms in the IL-23 receptor, which is necessary to promote differentiation of Th17 cells, as a risk factor for both $\mathrm{UC}$ and $\mathrm{CD}$, as well as other autoimmune diseases. ${ }^{22}$

\section{Current therapies in IBD Treating CD}

Patients with CD vary greatly in the severity and natural behavior of disease, age of onset, and localization of inflammation, which is partly captured in the widely used Montreal classification. ${ }^{23}$ The treatment of CD must be adapted and individualized to match this complexity, and in some cases, such as isolated ileal $\mathrm{CD}$ with structuring, primary surgical resection with subsequent secondary prevention using medications may be most appropriate. In other cases, primary medical treatment may be more appropriate, and there are indications that early use of powerful treatments may alter the natural history of disease and reduce long-term complications. In acute inflammatory $\mathrm{CD}$, systemic corticosteroids and anti-tumour necrosis factor (TNF) antibodies are effective at inducing a response in the majority of cases while 5-aminosalicylate (5-ASA) compounds are ineffective. ${ }^{24}$

Maintaining remission in CD relies on the use of immunosuppressants, primarily thiopurines or methotrexate. Anti-TNF agents such as infliximab and adalimumab are also effective, and are generally used where patients do not respond to orally administered immunosuppressants. Trials with the antibody to $\alpha_{4}$ integrin, natalizumab, showed efficacy in inducing and maintaining clinical response, although natalizumab is not widely used for this indication because of the risk of reactivation of JC virus infection, with potentially fatal consequences. ${ }^{25,26}$

Newer treatments for $\mathrm{CD}$ include the use of antibodies to IL-12/IL-23, such as ustekinumab, and antibody treatment 
against integrin, $\alpha_{4} \beta_{7}$, vedolizumab. ${ }^{27,28}$ The clinical effect of vedolizumab in inducing clinical response in active CD was modest, although maintenance treatment demonstrated sustained benefit. ${ }^{27}$ These emerging data demonstrate the complexity of $\mathrm{CD}$, and support the hypothesis that lymphocyte migration to the intestine contributes to disease and treatments targeting more specific cell populations may offer therapeutic benefits when administered in the appropriate context, such as maintenance versus induction of response.

\section{Treating UC}

The mainstay of treatment of UC is 5-ASA, which can be administered topically in the distal colon or rectum, and orally in a variety of formulations that limit systemic absorption in the small intestine and provide maximum exposure to the colonic mucosa. ${ }^{29}$ The aforementioned treatment is effective in inducing response in active disease, and maintaining remission in the chronic phase. Toxicity and side-effects are minimal, partly because of the low systemic exposure. When 5-ASA are inadequate to treat patients with $\mathrm{UC}$, topical and systemic corticosteroids are effective and are widely used to induce response in active disease. ${ }^{30}$ However, they are unsuited for long-term maintenance treatment because of the risk of side-effects, many of which are dose- and durationdependent, and potentially serious, such as osteoporosis, steroid-induced diabetes, and increased body mass index.

To maintain remission in cases where 5-ASA are insufficient, most patients are treated with immunosuppressants such as azathioprine, mercaptopurine, methotrexate, and tacrolimus. $^{31,32}$ In the UK and USA, the greatest experience is with the use of thiopurines, azathioprine and mercaptopurine (6-MP), and approximately $40 \%$ of patients with UC are treated with these drugs. ${ }^{31}$ Side effects from thiopurines are infrequent, although they can be serious and life threatening. They include bone marrow suppression, increased susceptibility to serious viral infections such as herpes simplex virus (HSV), Epstein-Barr virus (EBV), and cytomegalovirus (CMV), increased risk of lymphoma, and idiopathic inflammation including pancreatitis. ${ }^{33}$ In cases refractory to steroids and thiopurines, anti-TNF antibodies such as infliximab, adalimumab, and recently golimumab, have been shown to be effective in inducing and maintaining response in a proportion of cases. ${ }^{34}$ Most recently, the anti-integrin antibody, vedolizumab has also been shown to be effective in patients with $\mathrm{UC}$ who do not respond to the established treatments. ${ }^{35}$

In acute severe colitis (ASC), which presents with high stool frequency, rectal bleeding, and evidence of systemic inflammation, patients are hospitalized for treatment as the condition carries a risk of fatality, and a substantial risk of requiring a colectomy to treat medically uncontrollable colonic inflammation. ${ }^{36}$ The standard treatment of ASC includes high dose intravenous corticosteroid. Approximately $70 \%$ of patients respond clinically to this treatment. However, where this is ineffective, it is appropriate to consider colectomy or additional immunosuppression. The standard options in this situation are intravenous or oral cyclosporine, or intravenous infliximab and the efficacy of these treatments appears to be equal. ${ }^{37}$ However, in the longer term, approximately $40 \%$ of patients with ASC undergo colectomy, even if they initially have a clinical response to cyclosporine or infliximab. Newer agents such as vedolizumab have not yet been tested in the context of ASC.

Treatments to suppress the immune response show varying degrees of success in IBD, however there remains an unmet need for more targeted treatments, both to induce response in active disease, and to maintain remission potentially for decades without risking side effects, especially those arising from sustained general immune suppression. Furthermore, while many new treatments are based on therapeutic antibodies, there is a need for more cost-effective treatments that potentially could be produced more cheaply, and administered orally.

\section{Intestine specific homing versus in situ proliferation}

Active IBD is characterized by an accumulation of immune cells in the intestinal mucosa, including effector $\mathrm{T}$ cells. Effector T cells are thought to have a key role in disease through their cytotoxic activity and pro-inflammatory cytokine production. ${ }^{38,39}$ Strikingly, few T cells are actively proliferating in the human intestine; Fell et al demonstrated by immunohistochemical staining for Ki67 (marker of cell proliferation), that less than $1.5 \%$ of LP and follicular $\mathrm{CD}^{+} \mathrm{T}$ cells are proliferating in active $\mathrm{CD}$ and $\mathrm{UC} .^{40}$ Therefore, extravasation from the circulation into the tissue, and the retention of LP T cells must play a critical role in their accumulation during IBD. This is in contrast to mice, where models that resemble aspects of IBD, such as the $\mathrm{T}$ cell transfer model and dextran sodium sulfate (DSS)-induced colitis, have significant $\mathrm{T}$ cell proliferation within the intestinal LP. ${ }^{41-43}$ This is therefore an important difference between IBD and murine models of intestinal inflammation.

Cell extravasation from the peripheral blood into relevant tissue, such as the intestine, is a tightly regulated process, 


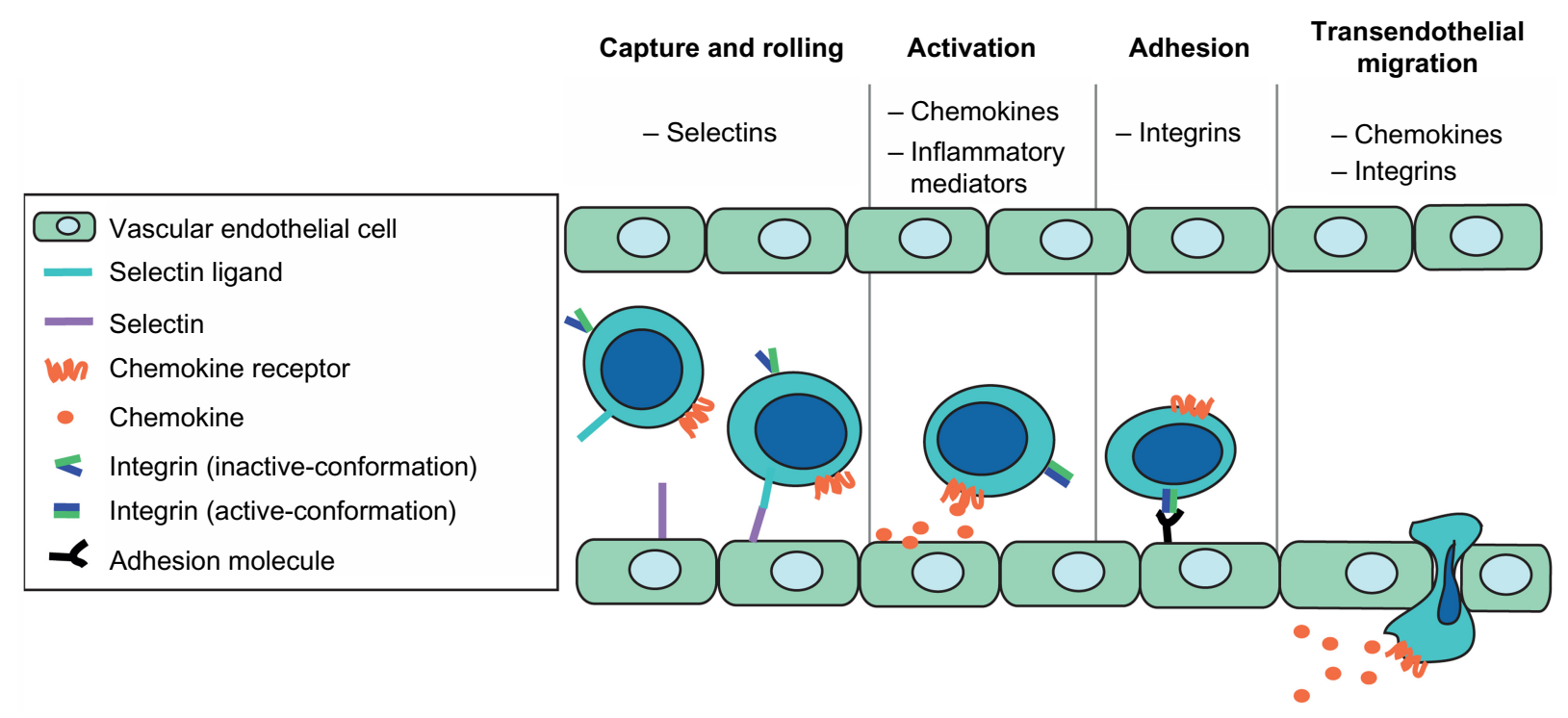

Figure I Chemokines promote leukocyte extravasation.

Notes: Interactions between selectins and selectin ligands form weak bonds that slow the flow of leukocytes, promoting initial cell capture and rolling. Leukocyte rolling allows chemokine receptors to bind cognate chemokine ligand, presented on the surface of endothelial cells. Chemokines promote integrin activation, and integrins mediate the firm adhesion of circulating leukocytes to vascular endothelial cells. Chemokines therefore promote cell extravasation by activating integrins and promoting directed cell migration. Adapted by permission from Macmillan Publishers Ltd: Nat Rev Immunol. Ley K, Laudanna C, Cybulsky MI, Nourshargh S. Getting to the site of inflammation: the leukocyte adhesion cascade updated. 2007;7(9):678-689.45 Copyright @ 2007. http://www.nature.com/nri/index.html.

mediated by members of the selectin, integrin, and chemokine protein families (Figure 1). Integrins are dimeric surface receptors composed of $\alpha$ and $\beta$ subunits that bind adhesion molecules to promote the firm adhesion of leukocytes to the vascular endothelium. On circulating cells, integrins remain in an inactive conformation, and in response to inflammatory mediators and chemokines, rapidly undergo conformational changes that activate their capacity for tight adhesion. ${ }^{44}$ Chemokines are chemoattractant cytokines that bind cognate chemokine receptors expressed on the surface of leukocytes. In addition to providing a chemotactic signal, chemokines facilitate integrin activation. ${ }^{45}$

The particular combination of surface integrins and chemokine receptors coordinate the movement of leukocytes to appropriate tissues. For example, T cells that express CCR4 and/or CCR10 in combination with cutaneous lymphocyte antigen have a characteristic skin homing phenotype. ${ }^{46,47}$ Cells that express CCR9 and integrin $\alpha_{4} \beta_{7}$ preferentially migrate to the intestine. ${ }^{48}$ CCR9 interacts with cognate ligand CCL25, predominantly expressed in the small intestinal mucosa. Integrin $\alpha_{4} \beta_{7}$ interacts with mucosal addressin cell adhesion molecule-1 (MAdCAM-1) and vascular cell adhesion molecule-1 (VCAM-1) present on mucosal endothelium and activated endothelium respectively. ${ }^{49-51}$

Naïve $T$ cells activated by dendritic cells situated in intestinal draining lymph nodes are preferentially induced to express CCR9 and integrin $\alpha_{4} \beta_{7}$, promoting recirculation to the intestine. ${ }^{52}$ Induction of CCR9 and $\alpha_{4} \beta_{7}$ expression is at least in part the result of exposure to the vitamin A metabolite, retinoic acid (RA). Iwata et al identified RA as a potent inducer of CCR9 and $\alpha_{4} \beta_{7}$ in vitro and demonstrated that dendritic cells from the gut associated lymphoid tissue express the enzymes necessary to catalyze the production of RA. ${ }^{48}$ In vivo, cells expressing CCR 9 and $\alpha_{4} \beta_{7}$ preferentially migrate to intestinal tissue. ${ }^{48}$

\section{CCR9 and CCL25 expression in healthy tissue}

In 1997, Vicari et al isolated CCL25 cDNA from the thymus of mice deficient in recombinase activation gene-1 ( $R A G-1)$; these mice have smaller lymphoid organs and do not produce mature B and T cells. ${ }^{53}$ CCL25 displayed high sequence homology to other members of the CC chemokine family, was found to be a potent chemoattractant for thymocytes, and was therefore designated Thymus Expressed ChemoKine (TECK). Although CCL25 was initially cloned from the thymus, abundant expression was also detected in the small intestine without expression in other tissues such as the liver, lung, and skin. ${ }^{53-55}$

In the intestinal tract of healthy mice, CCL25 expression is highest in the proximal small bowel (duodenum), decreases towards the distal small bowel (ileum), and is absent or near-absent in the colon. ${ }^{56-60}$ Characterization in the human intestinal tract has been less methodical, although constitutive CCL25 expression appears to be confined to the small intestine, with little or no expression in the stomach 
Table I CCR9 expression by cell type (human)

\begin{tabular}{|c|c|c|c|c|c|}
\hline \multirow[t]{2}{*}{ Cellular source } & \multicolumn{2}{|c|}{ CD3 } & \multirow[t]{2}{*}{ CD19 or CD20 } & \multirow[t]{2}{*}{ Other (pDC, m $\Phi)$} & \multirow[t]{2}{*}{ References } \\
\hline & CD4 & CD8 & & & \\
\hline Peripheral blood & $\sim 4$ & $\sim 2$ & $\sim 15$ & - & $54,61,62,91$ \\
\hline Small intestine lamina propria lymphocytes & $>60$ & $>60$ & $\sim 35$ & - & 61,91 \\
\hline Small intestine intraepithelial lymphocytes & - & $>90$ & - & - & 54 \\
\hline Colon lamina propria lymphocytes & $15-20$ & $10-15$ & $\sim 5$ & - & 61,91 \\
\hline
\end{tabular}

Notes: CCR9 expression in primary human cells isolated from the peripheral blood, small, and large intestine. Data show percentage of cells expressing CCR9 compiled from published data. Blank areas (-) indicate no published human data.

Abbreviations: pDC, plasmacytoid dendritic cells; $\mathrm{m} \Phi$, monocyte/macrophages; CCR9, CC chemokine receptor 9.

and colon..$^{51,53-55,61,62}$ In the human small intestine, the cellular source of CCL25 appears to be epithelial cells in the intestinal crypt, and potentially endothelial cells. ${ }^{55,61,62}$

CCL25 binds to and signals through a single chemokine receptor, CCR9, of which two alternative splicing variants, CCR9A and CCR9B have been identified. ${ }^{63}$ Among circulating leukocytes, CCR9 expression is restricted to a proportion of CD4 and CD8 T cells and activated B cells (Table 1). ${ }^{54,55,61,62,64,65,90,91}$ In mice, CCR9 has been identified on plasmacytoid dendritic cells, although relevant data in humans are lacking. ${ }^{66,67}$ Similarly, while some papers describe CCR9 expression on murine macrophages, human data are lacking. ${ }^{68}$ Within peripheral tissues, CCR9 ${ }^{+}$cells are enriched in the human thymus, small bowel, and colon. ${ }^{54,55,61}$ Intraepithelial lymphocytes are predominantly $\mathrm{CD} 8^{+}$, and the majority express surface CCR9. ${ }^{54,55}$

\section{Role of CCR9 and CCL25 in intestinal homing}

In vitro, CCL25 stimulates CCR9 dependent intracellular signaling, such as intracellular calcium flux and probably recruitment of $\beta$-arrestin proteins, and mediates directed cell migration. ${ }^{54,69}$ In vivo, CCR9/CCL25 interactions mediate CD4 and CD8 T cell homing to the small intestine, which is well described in mice (Table 2). Mice genetically deficient for either CCR9 or CCL25 (CCR9 ${ }^{-/-}$and CCL25 $5^{-/-}$respectively) are healthy, grow to adulthood, and are capable of breeding. ${ }^{70,71}$ However, in the small intestine, where CCL25 is constitutively expressed, the number of $\mathrm{CD} 8^{+}$intraepithelial lymphocytes and $\mathrm{CD} 8^{+}$LP lymphocytes is reduced by approximately $50 \%$. In contrast, the frequency of $\mathrm{CD}^{+} \mathrm{LP}$ lymphocytes is equivalent between wild-type, $\mathrm{CCR} 9^{-/-}$, and CCL25 $5^{-/}$mice suggesting a redundant role of CCR9 and CCL25 in the homeostatic migration of CD4 T cells to the intestine. $^{71}$

During inflammation in mice, CCR9 appears to mediate both $\mathrm{CD} 8$ and CD4 $\mathrm{T}$ cell homing to the small intestine. In a model of oral antigenic challenge, Wurbel et al used antigen specific CD8 T cells ( $\mathrm{T}$ cell receptor specific for ovalbumin [OVA]), adoptively transferred into CCL $25^{-/-}$mice and orally gavaged with OVA. Following OVA challenge, mice lacking CCL25 had significantly fewer CD8 T cell homing to the LP and epithelium. ${ }^{71}$ Similarly, in CD4 T cells, Stenstad et al reported that $\mathrm{CCR}^{-/-}$OVA specific $\mathrm{CD} 4 \mathrm{~T}$ cells were compromised in their homing to the small bowel following OVA challenge. ${ }^{72}$ Collectively these data demonstrate a role for CCR9 in homeostatic CD8 $\mathrm{T}$ cell homing, and a role in the homing of both CD4 and CD8 T cells to the small intestine in response to antigenic challenge.

\section{$\mathrm{CCR9}^{+} \mathrm{T}$ cells phenotype and effector function}

Peripheral blood $\mathrm{CCR} 9^{+} \mathrm{T}$ cells are predominantly effector

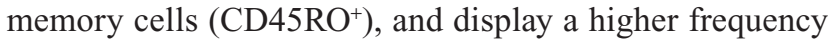
of activation markers, including CD25, CD69, OX40, and human leukocyte antigen-DR (HLA-DR) compared to $\mathrm{CCR}^{-} \mathrm{CD}^{+}{ }^{+} \mathrm{T}$ cells. ${ }^{64}$ Following in vitro activation, peripheral blood $\mathrm{CCR}^{+} \mathrm{T}$ cells predominantly produce IFN- $\gamma$ with a minor proportion producing IL-10, IL-2, and IL-4. ${ }^{64}$ Similar to circulating cells, $\mathrm{CD}^{+} \mathrm{CCR}^{+}$cells isolated from the small intestine predominantly produced IFN- $\gamma(47.8 \pm 4 \%$, $\mathrm{n}=5) .{ }^{73}$ In contrast, IL-10, IL-17, and IL-4 were produced by $7.2 \pm 1.8 \%, 10.1 \pm 1.7$, and $1.9 \pm 0.93 \%$ of $\mathrm{CCR}^{+} \mathrm{T}$ cells respectively, demonstrating a preferential Th1 polarization. ${ }^{73}$ Collectively, published data demonstrate that the majority of peripheral blood and intestinal CCR $9^{+}$cells are Th1 effector cells (producing IFN- $\gamma$ ), with a smaller proportion acting as Th17 effector cells (producing IL-17A) and a minority acting as regulatory $\mathrm{T}$ cell and Th2 cells (producing IL-10 and IL-4 respectively). ${ }^{61,64,73}$

\section{CCL25 and CCR9 in inflammation}

Traditionally, CCL25 and CCR9 have been regarded as a homeostatic chemokine and chemokine receptor pair, 
Table 2 Changes to murine CCR9+ $\mathrm{T}$ cell frequencies when CCR9 or CCL25 is genetically deleted

\begin{tabular}{|c|c|c|c|c|c|c|c|}
\hline & \multicolumn{2}{|c|}{$\begin{array}{l}\text { Small intestine lamina } \\
\text { propria lymphocytes }\end{array}$} & \multicolumn{2}{|c|}{$\begin{array}{l}\text { Small intestine } \\
\text { intraepithelial lymphocytes }\end{array}$} & \multicolumn{2}{|c|}{$\begin{array}{l}\text { Colon } \\
\text { mucosal lymphocytes }\end{array}$} & \multirow[t]{2}{*}{ References } \\
\hline & CD4 & CD8 & CD4 & CD8 & CD4 & CD8 & \\
\hline CCR9-/- & - & $\downarrow 50 \%$ & - & $\downarrow 50 \%$ & $n / d$ & $n / d$ & 70,71 \\
\hline $\mathrm{CCL} 25^{-/-}$ & - & $\downarrow 50 \%$ & - & $\downarrow 50 \%$ & $\mathrm{n} / \mathrm{d}$ & $\mathrm{n} / \mathrm{d}$ & 71 \\
\hline $\begin{array}{l}\text { Adoptive transfer of CD8 } \\
\text { cells into } \mathrm{CCL} 25^{-/-} \text {mice }\end{array}$ & & $\downarrow>50 \%$ & $n / d$ & $\downarrow>50 \%$ & & $\mathrm{n} / \mathrm{d}$ & 71 \\
\hline $\begin{array}{l}\text { Adoptive transfer } \\
\text { of CCR9 } 9^{--} \text {CD4 cells }\end{array}$ & $\downarrow 50 \%$ & & $n / d$ & & $n / d$ & & 72 \\
\hline
\end{tabular}

Note: Blank areas (-) indicates cell frequency is equivalent to wild-type mice, or there is no change compared to wild-type mice.

Abbreviations: CCR9, CC chemokine receptor 9; CCL25, CC ligand 25; n/d, no data.

however, there is increasing evidence that CCL25 can be induced by inflammation and that this chemokine-receptor pair can promote inflammation in particular contexts.

\section{Liver inflammation in primary sclerosing cholangitis}

In the healthy liver, CCL25 expression is low or undetected. ${ }^{53,54,74}$ In human hepatic inflammation, in primary sclerosing cholangitis (PSC), CCL25 expression was detected in the liver, expressed by portal dendritic cells and hepatic sinusoidal endothelial cells. ${ }^{74}$ The inflamed liver in PSC was also associated with an increased number of CCR9 positive $\mathrm{T}$ cells. Eksteen et al propose that long lived memory gut homing cells that express CCR9 and $\alpha_{4} \beta_{7}$, previously activated during episodes of IBD, exacerbate PSC by entering the liver through interactions with the hepatic vasculature that ectopically express CCL25 during PSC. ${ }^{74}$ The concept of $\mathrm{CCR}^{+}$cells disseminating inflammation is perhaps supported by observations made in a murine model of postoperative ileus.

\section{Intestinal inflammation in postoperative ileus}

Manipulation of the bowel during surgery or following abdominal trauma frequently leads to ileus, characterized by inflammation and intestinal dysmotility that typically lasts for 24 to 72 hours. ${ }^{75}$ The paralysis of peristalsis includes segments of the intestine that have not been operated on or manipulated, suggesting distant or systemic propagation of an inhibitory signal. In a murine model, Engel et al demonstrated that $\mathrm{CCR}^{+}$Th1 cells migrated from the small intestine and into the colon, where they induced ileus by IFN- $\gamma$ mediated activation of resident macrophages. ${ }^{76}$ Inhibition of the migration of lymphocytes using fingolimod, an inhibitor of sphingosine-1 receptors, prevented disease suggesting that cell recirculation contributed to the dissemination of disease. Interestingly, in patients who underwent abdominal surgery, the number of $\mathrm{CCR}^{+} \mathrm{CD}^{+}$IFN- $\gamma$ producing cells in the peripheral blood increased 10 fold after surgery, suggesting a possible role for CCR9 in human postoperative ileus. ${ }^{76}$

\section{CCL25 and CCR9 expression in IBD}

In two murine models of spontaneous ileitis $\left(\mathrm{TNF}^{\triangle \mathrm{ARE}}\right.$ and SAMP1/Yit models) CCL25 expression increased in the inflamed ileum. ${ }^{58,59}$ And in a murine model of colitis, CCL25 was detected in the inflamed colon following administration of DSS. ${ }^{60}$ Characterization of CCL25 expression in IBD is limited. An initial study from Papadakis et al, 2001 analyzed human tissue by IHC, and reported strong CCL25 staining adjacent to areas of $\mathrm{T}$ cell infiltration in the small intestine but not the colon. ${ }^{62}$ In a study of anti-TNF therapy in IBD, where gene expression was systematically studied before and after treatment, CCL25 expression in the ileum in CD compared to healthy controls was reported, although the difference was not statistically significant. ${ }^{51}$ However CCL25 mRNA expression in $\mathrm{CD}$ ileitis was increased compared to CD colitis. In this study, CCL25 was not detected in healthy colon, nor in the colon of patients with Crohn's colitis and UC. ${ }^{51}$

Papadakis et al reported that in active small bowel CD, the proportion of $\mathrm{CCR} 9^{+} \mathrm{CD}^{+}$cells in the peripheral blood was increased compared to healthy controls $(8.1 \%$ compared to $3.5 \%$ respectively); in contrast, patients with $\mathrm{CD}$ colitis had equivalent proportions of circulating CCR9 ${ }^{+} \mathrm{CD} 4^{+} \mathrm{T}$ cells. ${ }^{62}$ There are as yet no published data on CD8 T cells or on B cells, nor on CCR9 expression in UC and other gastroenterological or hepatological conditions. However CCL25 and CCR9 are implicated in PSC, and 75\%-90\% of patients with PSC also have IBD (mainly UC).$^{78}$ Therefore the connection between CCL25, CCR9, and UC in PSC patients warrants further investigation; in particular, one might hypothesize that patients with PSC have an altered distribution of CCL25 and $\mathrm{CCR}^{+}$cells within the colon.

In $\mathrm{CD}$, the proportion of $\mathrm{CCR} 9^{+} \mathrm{CD}^{+}$cells expressing activation markers CD25, CD69, OX40, CTLA4, CD40L, 


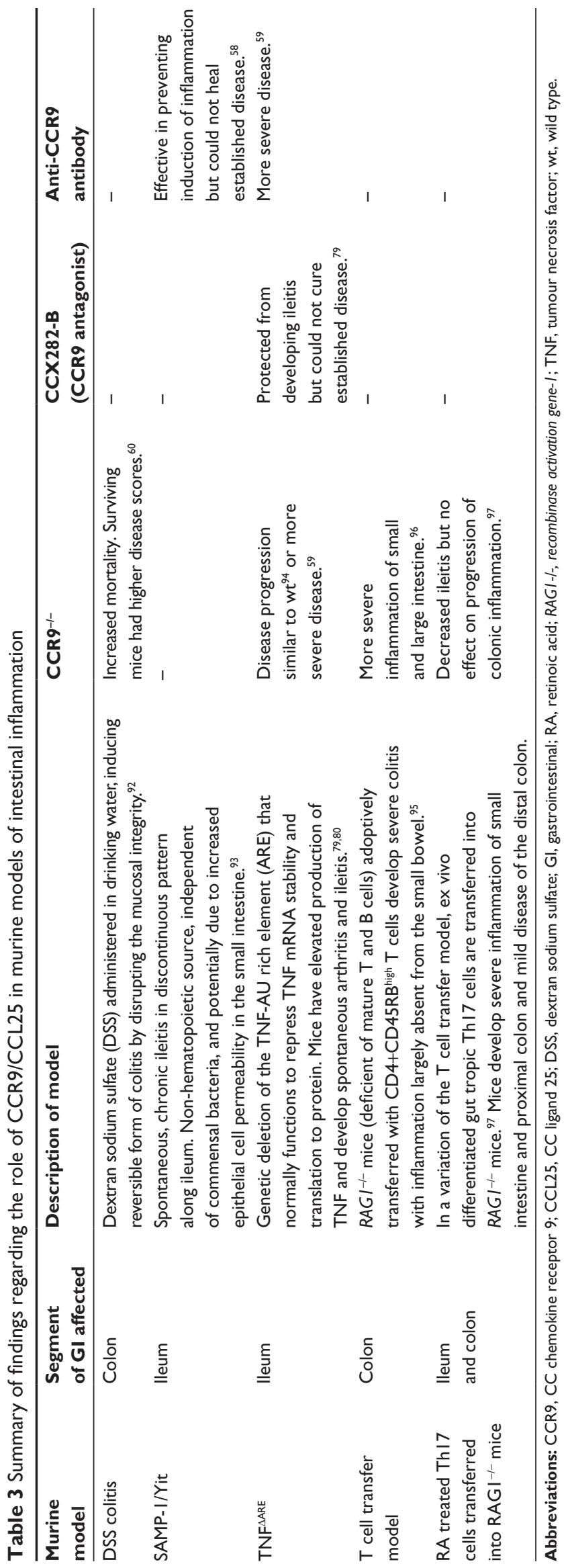

HLA-DR, and CD45RO was equal between healthy individuals and patients with $\mathrm{CD} \cdot{ }^{73}$ Furthermore, the proportion of CCR $9^{+} \mathrm{T}$ cells expressing cytokines IFN- $\gamma$, IL-10, IL-17, and IL-4 was equal between cells isolated from the normal small bowel (SB) and CD SB, with preferential IFN- $\gamma$ production. ${ }^{73}$ Whilst the proportion of $\mathrm{CCR} 9^{+}$cells producing cytokines was equal in normal and $\mathrm{CD} \mathrm{SB}$, the amount of IFN- $\gamma$ and IL- 17 protein produced by $\mathrm{CCR} 9^{+} \mathrm{CD}^{+}$ cells was significantly greater for cells isolated from the SB CD than from healthy control SB. ${ }^{73}$ Based upon the predominant pro-inflammatory effector function of CCR $9^{+}$ $\mathrm{T}$ cells, intestinal homing specificity, and increased circulating frequency during $\mathrm{CD}$, antagonizing the $\mathrm{CCR} 9$ receptor was hypothesized as a target in $\mathrm{CD}$. The preclinical and clinical studies testing CCR9 antagonist treatment in CD are reviewed next.

\section{Preclinical use of CCR9 antagonist}

The only reported pharmacological antagonist of CCR9 is a compound developed by ChemoCentryx, Inc., Mountain View, CA, USA, initially designated CCX282-B, and later GSK-1605786 or vercirnon. ${ }^{79}$ Effects of this inhibitor, which is bio-available in the circulation following oral administration, and which has high specificity for CCR9 with negligible binding to any other chemokine receptor, have been evaluated in murine models of IBD as well as in clinical trials. The published data are reviewed in the next section.

\section{Cell migration and calcium flux, in vitro}

Preclinical studies of CCX282-B performed by ChemoCentryx demonstrate potent and specific inhibition of CCR9 mediated intracellular calcium mobilization and cell migration. Measured by chemotaxis, CCX282-B inhibits CCR9 mediated chemotaxis to CCL25 (50\% inhibition concentration $\left[\mathrm{IC}_{50}\right]<7 \mathrm{nM}$ ), measured in the Molt-4 cells, CCR9 transfected cell lines, primary derived human $\mathrm{T}$ cells, and murine and rat thymocytes. ${ }^{79}$ Applying a combination of calcium flux and competitive binding assays, CCX282-B did not antagonize nor bind any of the other 18 chemokine receptors, demonstrating CCR9 specificity.

\section{Murine model of ileitis}

In vivo, CCX282-B protected TNF ${ }^{\triangle A R E}$ mice from developing spontaneous ileitis. ${ }^{79}$ In this model, genetic deletion of the TNF-AU rich element (ARE), an element that normally functions to repress TNF mRNA stability and translation 
to protein, causes mice to have elevated production of TNF; consequently TNF ${ }^{\triangle \mathrm{ARE}}$ mice develop spontaneous arthritis and ileitis, with intestinal pathology resembling aspects of CD. ${ }^{79,80}$ At weeks 4,8 , and 20 of age, intestinal disease is minimal, peaks, and plateaus respectively. In the ileum, levels of CCL25 were elevated in inflamed tissue. At 12 weeks of age, approximately $80 \%$ of $\mathrm{TNF}^{\triangle \mathrm{ARE}}$ mice had moderate to severe intestinal inflammation. Mice treated with CCX282-B (between weeks 2-12, twice daily by subcutaneous injection) had a significant reduction in inflammation, with $30 \%$ incidence of moderate disease and no cases of severe disease. ${ }^{79}$ The data from these experiments and other preclinical investigation of CCR9 and CCL25 are summarized in Table 3.

\section{Clinical use of CCR9 antagonist Phase Ilb studies of CCX282-B (PROTECT-I)}

The clinical efficacy of CCX282-B in CD was tested in a Phase IIb study termed the Prospective Randomized Oral Therapy Evaluation in Crohn's disease Trial 1 (PROTECT-1), in which a total of 436 patients were enrolled, and randomly assigned to one of four treatment groups: ${ }^{81,82}$

- $\quad$ placebo twice daily $(\mathrm{n}=144)$;

- $250 \mathrm{mg}$ CCX282-B once daily ( $\mathrm{n}=98)$;

- 250 mg CCX282-B twice daily $(n=96)$;

- $500 \mathrm{mg}$ CCX282-B once daily $(\mathrm{n}=97){ }^{81}$

PROTECT-1 was organized into three study stages:

- Induction period: measuring induction of a clinical response at weeks 8 and 12. Conventional randomized, double-blind, placebo-controlled study testing three different doses of CCX282-B.

- Active period: open-label study in which eligible participants received CCX282-B at a dose of $250 \mathrm{mg}$ twice daily.

- Maintenance period: subjects who had a clinical response following the active period were re-randomized to receive placebo or CCX282-B at a dose of $250 \mathrm{mg}$ twice daily.

The primary endpoint for the induction period of PRO-

TECT-1 was a statistically significant reduction in the CD activity index (CDAI) of 70 points at week 8 of treatment, and this was not met. ${ }^{82}$ However, at week 12 , significantly more patients on $500 \mathrm{mg}$ daily of CCX282-B had a clinical response compared to placebo (61\% versus $47 \%$, respectively, $P=0.039) .{ }^{82}$ At week 12 , response rates were similar between patient groups receiving $250 \mathrm{mg}$ CCX282-B once daily or twice daily, or twice daily placebo $(56 \%, 49 \%$, and $47 \%$ respectively). This conundrum, of a differential response to a single dose of $500 \mathrm{mg}$ daily, versus $250 \mathrm{mg}$ twice daily, may relate to lower peak serum concentrations of the drug in patients receiving $250 \mathrm{mg}$ twice daily, compared to $500 \mathrm{mg}$ once daily. At week $12,41 \%$ of subjects on CCX282-B were in corticosteroid-free remission, compared to $28 \%$ on placebo $(P=0.041)$.

Following the 12 week induction period, patients were subsequently offered 4 weeks of active treatment $(250 \mathrm{mg}$ twice daily). This period gave all patients the opportunity to receive active treatment from weeks 12-16 of enrollment. At week 16, patients who showed a clinical response defined as a drop in CDAI of $\geq 70$ points were re-randomized to receive placebo or CCX282-B (250 $\mathrm{mg}$ twice daily) in the maintenance stage.

The primary endpoint for the maintenance period was maintaining a sustained clinical response at the end of 36 weeks; loss of response was defined as an increase in CDAI $>70$ points or an increase above 250 . In this study CCX282-B $250 \mathrm{mg}$ twice daily was more effective than placebo at maintaining remission: $47 \%$ of patients on CCX282-B compared to $31 \%$ of placebo $(P=0.012)$. Secondary endpoints also suggested some benefit in maintenance, for instance the median C-reactive protein (CRP) levels decreased from 12.6 $\mathrm{mg} / \mathrm{L}$ to $8.7 \mathrm{mg} / \mathrm{L}$ in the CCX282-B patient group, compared to $14.1 \mathrm{mg} / \mathrm{L}$ to $12.3 \mathrm{mg} / \mathrm{L}$ in the placebo patient group; median CDAI decreased in the CCX282-B patient group (128 to 95$)$ and increased in the placebo group (136 to 146) ${ }^{82}$

\section{Phase III studies of vercirnon (SHIELD-I)}

Following the outcome of the PROTECT-1 study, further development of CCX282-B was sponsored by GlaxoSmithKline (GSK) plc, Brentford, UK, as part of a partnership alliance with ChemoCentryx Inc. As part of this collaboration, four Phase III trials in CD were initiated, termed Study in CroHn's Disease Patients Investigating the Efficacy and Safety of an OraLly Dosed CCR9 (SHIELD) 1, 2, 3, and 4. CCX282-B was reformulated and renamed, initially GSK1605786 Formulation A (GSK1605786A), and subsequently vercirnon. ${ }^{83-86}$

SHIELD-1 was a randomized, double blind placebo controlled study to evaluate the efficacy and safety of vercirnon $500 \mathrm{mg}$ once daily or $500 \mathrm{mg}$ twice daily over 12 weeks in patients with moderate to severe CD. The SHIELD program was terminated in August 2013, after 605 patients had been recruited into SHIELD-1. ${ }^{83}$ Although the data have not yet been published in the literature, they were presented at the American College of Gastroenterology annual conference in October 2013, and showed that there were no significant 
differences in clinical response or other endpoints between placebo and either dose of vercirnon. Serious adverse events and withdrawals due to adverse events were similar between the treatment groups. SHIELD-3, which was designed to test efficacy in maintenance was also terminated, and there were insufficient data to determine if there was a positive effect of vercirnon in maintenance. ${ }^{84}$

The discrepancy in outcome between the Phase $\mathrm{IIb}$ PROTECT-1 study and the Phase III SHIELD-1 study remains unexplained, and may be related in part to differences in the patients recruited. For instance, the number of patients previously exposed to anti-TNF treatment in SHIELD-1 was $69 \%$, compared to $26 \%$ in PROTECT-1. Unfortunately, although CCX282-B had a positive effect in maintenance in PROTECT-1, maintenance ultimately was not tested in the SHIELD program. ${ }^{84}$

\section{Safety and tolerability of CCR9 antagonists}

In Phase II trials in patients with moderate-to-severe CD (estimated enrollment of 70 individuals), CCX282-B was well tolerated and the incidence of adverse events was comparable between patients assigned placebo and CCX282-B. ${ }^{89}$ In the Phase IIb PROTECT-1 trial $(\mathrm{n}=436)$, where patients received CCX282-B for up to 52 weeks, the drug was well tolerated: the number of patients reporting adverse events was comparable between treatment groups and placebo, and there was no indication of an increased risk of infection, in the intestine, or systemically. ${ }^{81}$

\section{Conclusion}

$\mathrm{CCR}^{+}$cells are predominantly Th1 effector memory $\mathrm{T}$ cells that are enriched in the small intestine $(>60 \%)$ and colon $(\sim 20 \%)$ compared to the peripheral blood $(<5 \%)$, and are found at an increased frequency in the peripheral blood in some patients with CD. The results of clinical trials antagonizing CCR9 in CD have been variable: the Phase IIb PROTECT-1 study showed efficacy at inducing and maintaining remission compared to placebo, while the more recent SHIELD-1 study did not find any effect in inducing remission. Unfortunately the planned Phase III study to determine if CCR9 blockade could maintain remission was abandoned when the SHIELD program was terminated, although this remains a strong indication for a CCR9 antagonist treatment and an unmet clinical need for patients.

Possible explanations for the different results in PROTECT-1 and SHIELD-1 include differences in patients enrolled. Both studies recruited patients with mild-to-moderate
CD, however, the lower limit of CDAI in PROTECT-1 was higher than in SHIELD-1, and the threshold CRP for entry was also higher in PROTECT-1 than in SHIELD-1. Furthermore, the SHIELD-1 study included proportionately more patients who had previously been treated with anti-TNF therapy $(69 \%$ versus $26 \%$ ). The trial designs were also different, and the rate of discontinuation was higher in SHIELD-1 compared to PROTECT-1 (25\% versus 16\%).

Clinical and pre-clinical studies to determine the effect of antagonizing CCR9 in IBD have produced varied and sometimes conflicting results. Targeting CCR9 prevented the induction of ileal disease, as determined in a Th17-specific variant of the $\mathrm{RAG}^{-/}$adoptive transfer model, the SAMP-1/ Yit model and TNF ${ }^{\triangle \mathrm{ARE}}$ model. However, in the DSS and $\mathrm{RAG}^{-/-}$transfer models of colonic inflammation, disease was either unaffected by, or exacerbated by the lack of CCR9. However, in human studies, there remains the potential benefit of blocking CCR9 to maintain disease remission in $\mathrm{CD}$, and possibly to ameliorate colonic CD and UC.

Although the proportion of $\mathrm{CCR}^{+}$cells in the colon, at approximately $20 \%$, is lower than in the small intestine there may be evidence that these cells contribute to colonic IBD. In the PROTECT-1 trial, the subgroup of patients with colonic disease appeared to respond better than patients with isolated small bowel CD. Eberhardson et al recently reported the successful treatment of a patient with active $\mathrm{UC}$, using a technique to remove CCR9 positive cells from the circulation by means of leukocytapheresis with an immobilized CCL25 matrix. ${ }^{87}$ These observations, together with the marked benefit of vedolizumab (anti- $\alpha_{4} \beta_{7}$ ) in UC, suggest that targeting CCR9 therapeutically in UC should be considered for investigation. ${ }^{35}$ Similarly, studies to target CCR9 and $\alpha_{4} \beta_{7}$ integrin in PSC are supported by clinical and experimental data. ${ }^{76,88}$

To make further progress in delineating the potential clinical role of CCR9 in human disease, detailed mechanistic studies, and well-designed proof-of-concept human trials are now required. These should include studying the interaction between CCR 9 and $\alpha_{4} \beta_{7}$ integrin, and determining the effects of blocking CCR9 on the activation state of circulating and tissue-infiltrating lymphocytes. Maintaining disease remission in $\mathrm{CD}$ remains a strong indication for CCR9 antagonist treatment, and any future clinical trials should include patients with $\mathrm{UC}$ and with PSC, where CCR9 may play a key role.

\section{Disclosure}

Dr Keshav has provided consultancy services for a number of pharmaceutical and healthcare companies including Abbvie, Astra-Zeneca, ChemoCentryx, Dr Falk Pharma, 
Ferring, GSK, MSD, Mitsubishi Pharma, Pfizer, Vifor, and Warner-Chilcott, and received research support from ChemoCentryx, MSD, and Warner-Chilcott. Dr Wendt has received grant support and reagents from ChemoCentryx Inc.

\section{References}

1. Loftus EV JR. Clinical epidemiology of inflammatory bowel disease: Incidence, prevalence, and environmental influences. Gastroenterology. 2004;126(6):1504-1517.

2. Molodecky NA, Soon IS, Rabi DM, et al. Increasing incidence and prevalence of the inflammatory bowel diseases with time, based on systematic review. Gastroenterology. 2012;142(1):46-54.

3. Abraham C, Cho JH. Inflammatory bowel disease. $N$ Engl $J$ Med. 2009;361(21):2066-2078.

4. White GE, Iqbal AJ, Greaves DR. CC chemokine receptors and chronic inflammation - therapeutic opportunities and pharmacological challenges. Pharmacol Rev. 2013;65(1):47-89.

5. Charo IF, Ransohoff RM. The many roles of chemokines and chemokine receptors in inflammation. $N$ Engl J Med. 2006;354(6):610-621.

6. Ahmad T, Armuzzi A, Bunce M, et al. The molecular classification of the clinical manifestations of Crohn's disease. Gastroenterology. 2002;122(4):854-866.

7. Freeman HJ. Granuloma-positive Crohn's disease. Can J Gastroenterol. 2007;21(9):583-587.

8. Oberhuber G, Stangl PC, Vogelsang H, Schober E, Herbst F, Gasche C. Significant association of strictures and internal fistula formation in Crohn's disease. Virchows Arch. 2000;437(3):293-297.

9. Kobayashi T, Okamoto S, Hisamatsu T, et al. IL23 differentially regulates the Th1/Th17 balance in ulcerative colitis and Crohn's disease. Gut. 2008;57(12):1682-1689.

10. Fuss IJ, Neurath M, Boirivant $M$, et al. Disparate $C D 4^{+}$lamina propria (LP) lymphokine secretion profiles in inflammatory bowel disease. J Immunol. 1996;157(3):1261-1270.

11. Parronchi P, Romagnani P, Annunziato F, et al. Type 1 T-helper cell predominance and interleukin-12 expression in the gut of patients with Crohn's disease. Am J Pathol. 1997;150(3):823-832.

12. Fais S, Capobianchi MR, Pallone F, et al. Spontaneous release of interferon gamma by intestinal lamina propria lymphocytes in Crohn's disease. Kinetics of in vitro response to interferon gamma inducers. Gut. 1991;32(4):403-407.

13. Breese E, Braegger CP, Corrigan CJ, Walker-Smith JA, MacDonald TT. Interleukin-2- and interferon-gamma-secreting $\mathrm{T}$ cells in normal and diseased human intestinal mucosa. Immunology. 1993;78(1): $127-131$.

14. Monteleone G, Biancone L, Marasco R, et al. Interleukin 12 is expressed and actively released by Crohn's disease intestinal lamina propria mononuclear cells. Gastroenterology. 1997;112(4):1169-1178.

15. Okazawa A, Kanai T, Watanabe M, et al. Th1-mediated intestinal inflammation in Crohn's disease may be induced by activation of lamina propria lymphocytes through synergistic stimulation of interleukin-12 and interleukin-18 without T cell receptor engagement. Am J Gastroenterol.2002;97(12):3108-3117.

16. Swain SL, Mckinstry KK, Strutt TM. Expanding roles for CD4+ T cells in immunity to viruses. Nat Rev Immunol. 2012;12(2):136-148.

17. Fuss IJ, Heller F, Boirivant M, et al. Nonclassical CD1d-restricted NK $\mathrm{T}$ cells that produce IL-13 characterize an atypical Th2 response in ulcerative colitis. J Clin Invest. 2004;113(10):1490-1497.

18. Heller F, Florian P, Bojarski C, et al. Interleukin-13 is the key effector Th2 cytokine in ulcerative colitis that affects epithelial tight junctions, apoptosis, and cell restitution. Gastroenterology. 2005; 129(2):550-564.

19. Neurath MF, Finotto S, Glimcher LH. The role of Th1/Th2 polarization in mucosal immunity. Nat Med. 2002;8(6):567-573.

20. Fujino S, Andoh A, Bamba S, et al. Increased expression of interleukin 17 in inflammatory bowel disease. Gut. 2003;52(1):65-70.
21. Ouyang W, Kolls JK, Zheng Y. The biological functions of T helper 17 cell effector cytokines in inflammation. Immunity. 2008;28(4): 454-467.

22. Duerr RH, Taylor KD, Brant SR, et al. A genome-wide association study identifies IL23R as an inflammatory bowel disease gene. Science. 2006;314(5804):1461-1463.

23. Satsangi J, Silverberg MS, Vermeire S, Colombel JF. The Montreal classification of inflammatory bowel disease: controversies, consensus, and implications. Gut. 2006;55(6):749-753.

24. Cummings JR, Keshav S, Travis SP. Medical management of Crohn's disease. BMJ. 2008;336(7652):1062-1066.

25. Kane SV, Horst S, Sandborn WJ, et al. Natalizumab for moderate to severe Crohn's disease in clinical practice: the Mayo Clinic Rochester experience. Inflamm Bowel Dis. 2012;18(12):2203-2208.

26. Van Assche G, Van Ranst M, Sciot R, et al. Progressive multifocal leukoencephalopathy after natalizumab therapy for Crohn's disease. $N$ Engl J Med. 2005;353(4):362-368.

27. Sandborn WJ, Feagan BG, Rutgeerts P, et al. Vedolizumab as induction and maintenance therapy for Crohn's disease. $N$ Engl $J$ Med. 2013;369(8):711-721.

28. Sandborn WJ, Gasink C, Gao LL, et al. Ustekinumab induction and maintenance therapy in refractory Crohn's disease. $N$ Engl $J$ Med. 2012;367(16):1519-1528

29. Greenfield SM, Punchard NA, Teare JP, Thompson RP. Review article: the mode of action of the aminosalicylates in inflammatory bowel disease. Aliment Pharmacol Ther. 1993;7(4):369-383.

30. Ford AC, Bernstein CN, Khan KJ, et al. Glucocorticosteroid therapy in inflammatory bowel disease: systematic review and meta-analysis. $\mathrm{Am}$ J Gastroenterol. 2011;106(4):590-599.

31. Ramadas AV, Gunesh S, Thomas GA, Williams GT, Hawthorne AB. Natural history of Crohn's disease in a population-based cohort from Cardiff (1986-2003): a study of changes in medical treatment and surgical resection rates. Gut. 2010;59(9):1200-1206.

32. Nielsen OH, Vainer B, Rask-Madsen J. Review article: the treatment of inflammatory bowel disease with 6-mercaptopurine or azathioprine. Aliment Pharmacol Ther. 2001;15(11):1699-1708

33. Saibeni S, Virgilio T, D'Inca R, et al. The use of thiopurines for the treatment of inflammatory bowel diseases in clinical practice. Dig Liver Dis. 2008;40(10):814-820.

34. Danese S, Colombel JF, Peyrin-Biroulet L, Rutgeerts P, Reinisch W. Review article: the role of anti-TNF in the management of ulcerative colitis - past, present and future. Aliment Pharmacol Ther. 2013;37(9):855-866.

35. Feagan BG, Rutgeerts P, Sands BE, et al. Vedolizumab as induction and maintenance therapy for ulcerative colitis. $N$ Engl $J$ Med. 2013;369(8):699-710.

36. Travis SP. Review article: the management of mild to severe acute ulcerative colitis. Aliment Pharmacol Ther. 2004;20 Suppl 4:88-92.

37. Laharie D, Bourreille A, Branche J, et al. Ciclosporin versus infliximab in patients with severe ulcerative colitis refractory to intravenous steroids: a parallel, open-label randomised controlled trial. Lancet. 2012;380(9857):1909-1915.

38. Shale M, Schiering C, Powrie F. CD4(+) T-cell subsets in intestinal inflammation. Immunol Rev. 2013;252(1):164-182.

39. Lee JC, Lyons PA, McKinney EF, et al. Gene expression profiling of $\mathrm{CD} 8^{+} \mathrm{T}$ cells predicts prognosis in patients with Crohn disease and ulcerative colitis. J Clin Invest. 2011;121(10):4170-4179.

40. Fell JM, Walker-Smith JA, Spencer J, MacDonald TT. The distribution of dividing T cells throughout the intestinal wall in inflammatory bowel disease (IBD). Clin Exp Immunol. 1996;104(2):280-285.

41. Feng T, Wang L, Schoeb TR, Elson CO, Cong Y. Microbiota innate stimulation is a prerequisite for $\mathrm{T}$ cell spontaneous proliferation and induction of experimental colitis. J Exp Med. 2010;207(6): 1321-1332.

42. Mottet C, Uhlig HH, Powrie F. Cutting edge: cure of colitis by $\mathrm{CD}^{+}{ }^{+} \mathrm{CD} 25^{+}$regulatory T cells. J Immunol. 2003;170(8): 3939-3943. 
43. Dutra RC, Claudino RF, Bento AF, et al. Preventive and therapeutic euphol treatment attenuates experimental colitis in mice. PloS One. 2011;6(11):e27122.

44. Weber C, Alon R, Moser B, Springer TA. Sequential regulation of alpha 4 beta 1 and alpha 5 beta 1 integrin avidity by $\mathrm{CC}$ chemokines in monocytes: implications for transendothelial chemotaxis. J Cell Biol. 1996;134(4):1063-1073.

45. Ley K, Laudanna C, Cybulsky MI, Nourshargh S. Getting to the site of inflammation: the leukocyte adhesion cascade updated. Nat Rev Immunol. 2007;7(9):678-689.

46. Robert C, Kupper TS. Inflammatory skin diseases, T cells, and immune surveillance. N Engl J Med. 1999;341(24):1817-1828.

47. Campbell JJ, Haraldsen G, Pan J, et al. The chemokine receptor CCR4 in vascular recognition by cutaneous but not intestinal memory $\mathrm{T}$ cells Nature. 1999;400(6746):776-780.

48. Iwata M, Hirakiyama A, Eshima Y, Kagechika H, Kato C, Song SY. Retinoic acid imprints gut-homing specificity on T cells. Immunity. 2004;21(4):527-538

49. Arihiro S, Ohtani H, Suzuki M, et al. Differential expression of mucosal addressin cell adhesion molecule-1 (MAdCAM-1) in ulcerative colitis and Crohn's disease. Pathol Int. 2002;52(5-6):367-374.

50. Connor EM, Eppihimer MJ, Morise Z, Granger DN, Grisham MB Expression of mucosal addressin cell adhesion molecule-1 (MAdCAM-1) in acute and chronic inflammation. J Leukoc Biol. 1999;65(3) 349-355.

51. Arijs I, De Hertogh G, Machiels K, et al. Mucosal gene expression of cell adhesion molecules, chemokines, and chemokine receptors in patients with inflammatory bowel disease before and after infliximab treatment. Am J Gastroenterol. 2011;106(4):748-761.

52. Agace W. Generation of gut-homing $\mathrm{T}$ cells and their localization to the small intestinal mucosa. Immunol Lett. 2010;128(1):21-23.

53. Vicari AP, Figueroa DJ, Hedrick JA, et al. TECK: a novel CC chemokine specifically expressed by thymic dendritic cells and potentially involved in T cell development. Immunity. 1997;7(2):291-301.

54. Zabel BA, Agace WW, Campbell JJ, et al. Human G protein-coupled receptor GPR-9-6/CC chemokine receptor 9 is selectively expressed on intestinal homing $\mathrm{T}$ lymphocytes, mucosal lymphocytes, and thymocytes and is required for thymus-expressed chemokine-mediated chemotaxis J Exp Med. 1999;190(9):1241-1256.

55. Kunkel EJ, Campbell JJ, Haraldsen G, et al. Lymphocyte CC chemokine receptor 9 and epithelial thymus-expressed chemokine (TECK) expression distinguish the small intestinal immune compartment: Epithelial expression of tissue-specific chemokines as an organizing principle in regional immunity. $J$ Exp Med. 2000;192(5):761-768.

56. Svensson M, Marsal J, Ericsson A, et al. CCL25 mediates the localization of recently activated CD8alphabeta(+) lymphocytes to the smallintestinal mucosa. J Clin Invest. 2002;110(8):1113-1121.

57. Stenstad H, Svensson M, Cucak H, Kotarsky K, Agace WW. Differential homing mechanisms regulate regionalized effector $\mathrm{CD} 8$ alphabeta+ $\mathrm{T}$ cell accumulation within the small intestine. Proc Natl Acad Sci USA. 2007;104(24):10122-10127.

58. Rivera-Nieves J, Ho J, Bamias G, et al. Antibody blockade of CCL25/ CCR9 ameliorates early but not late chronic murine ileitis. Gastroenterology. 2006;131(5):1518-1529.

59. Wermers JD, McNamee EN, Wurbel MA, Jedlicka P, Rivera-Nieves J. The chemokine receptor CCR9 is required for the T cell-mediated regulation of chronic ileitis in mice. Gastroenterology. 2011;140(5): 1526-1535.

60. Wurbel MA, McIntire MG, Dwyer P, Fiebiger E. CCL25/CCR9 interactions regulate large intestinal inflammation in a murine model of acute colitis. PloS One. 2011;6(1):e16442.

61. Papadakis KA, Prehn J, Nelson V, et al. The role of thymusexpressed chemokine and its receptor CCR9 on lymphocytes in the regional specialization of the mucosal immune system. J Immunol. 2000;165(9):5069-5076.

62. Papadakis KA, Prehn J, Moreno ST, et al. CCR9-positive lymphocytes and thymus-expressed chemokine distinguish small bowel from colonic Crohn's disease. Gastroenterology. 2001;121(2):246-254.
63. Yu CR, Peden KW, Zaitseva MB, Golding H, Farber JM. CCR9A and CCR9B: two receptors for the chemokine CCL25/TECK/ $\mathrm{Ck}$ beta-15 that differ in their sensitivities to ligand. J Immunol. 2000;164(3):1293-1305.

64. Papadakis KA, Landers C, Prehn J, et al. CC chemokine receptor 9 expression defines a subset of peripheral blood lymphocytes with mucosal T cell phenotype and Th1 or T-regulatory 1 cytokine profile. J Immunol. 2003;171(1):159-165.

65. Berahovich RD, Lai NL, Wei Z, Lanier LL, Schall TJ. Evidence for NK cell subsets based on chemokine receptor expression. J Immunol. 2006;177(11):7833-7840.

66. Wendland M, Czeloth N, Mach N, et al. CCR9 is a homing receptor for plasmacytoid dendritic cells to the small intestine. Proc Natl Acad Sci US A. 2007;104(15):6347-6352.

67. Hadeiba H, Lahl K, Edalati A, et al. Plasmacytoid dendritic cells transport peripheral antigens to the thymus to promote central tolerance. Immunity. 2012;36(3):438-450.

68. Nakamoto N, Ebinuma H, Kanai T, et al. CCR9 ${ }^{+}$macrophages are required for acute liver inflammation in mouse models of hepatitis. Gastroenterology. 2012;142(2):366-376.

69. Luttrell LM, Lefkowitz RJ. The role of beta-arrestins in the termination and transduction of G-protein-coupled receptor signals. J Cell Sci. 2002;115(Pt 3):455-465.

70. Wurbel MA, Malissen M, Guy-Grand D, et al. Mice lacking the CCR9 CC-chemokine receptor show a mild impairment of early $\mathrm{T}$ - and B-cell development and a reduction in T-cell receptor gammadelta(+) gut intraepithelial lymphocytes. Blood. 2001;98(9): 2626-2632.

71. Wurbel MA, Malissen M, Guy-Grand D, Malissen B, Campbell JJ. Impaired accumulation of antigen-specific CD8 lymphocytes in chemokine CCL25-deficient intestinal epithelium and lamina propria. J Immunol. 2007;178(12):7598-7606.

72. Stenstad H, Ericsson A, Johansson-Lindbom B, et al. Gutassociated lymphoid tissue-primed $\mathrm{CD}^{+} \mathrm{T}$ cells display CCR9dependent and -independent homing to the small intestine. Blood. 2006;107(9):3447-3454.

73. Saruta M, Yu QT, Avanesyan A, Fleshner PR, Targan SR, Papadakis KA. Phenotype and effector function of CC chemokine receptor 9-expressing lymphocytes in small intestinal Crohn's disease. J Immunol. 2007;178(5):3293-3300.

74. Eksteen B, Grant AJ, Miles A, et al. Hepatic endothelial CCL25 mediates the recruitment of $\mathrm{CCR}^{+}$gut-homing lymphocytes to the liver in primary sclerosing cholangitis. J Exp Med. 2004;200(11): 1511-1517.

75. Holte K, Kehlet H. Postoperative ileus: a preventable event. Br J Surg. 2000;87(11):1480-1493.

76. Engel DR, Koscielny A, Wehner S, et al. T helper type 1 memory cells disseminate postoperative ileus over the entire intestinal tract. Nat Med. 2010;16(12):1407-1413.

77. Pollheimer MJ, Halilbasic E, Fickert P, Trauner M. Pathogenesis of primary sclerosing cholangitis. Best Pract Res Clin Gastroenterol. 2011;25(6):727-739.

78. Molodecky NA, Kareemi H, Parab R, et al. Incidence of primary sclerosing cholangitis: a systematic review and meta-analysis. Hepatology. 2011;53(5):1590-1599.

79. Walters MJ, Wang Y, Lai N, et al. Characterization of CCX282-B, an orally bioavailable antagonist of the CCR9 chemokine receptor, for treatment of inflammatory bowel disease. J Pharmacol Exp Ther. 2010;335(1):61-69.

80. Kontoyiannis D, Pasparakis M, Pizarro TT, Cominelli F, Kollias G. Impaired on/off regulation of TNF biosynthesis in mice lacking TNF AU-rich elements: implications for joint and gut-associated immunopathologies. Immunity. 1999;10(3):387-398.

81. ChemoCentryx. A study to evaluate the efficacy and safety of CCX282$\mathrm{B}$ in subjects with moderate to severe Crohn's disease. Available from: http://clinicaltrials.gov/show/NCT00306215. NLM Identifier: NCT00306215. Accessed August 2, 2014. 
82. Keshav S, Vaňásek T, Niv Y, et al. A randomized controlled trial of the efficacy and safety of CCX282-B, an orally-administered blocker of chemokine receptor CCR9, for patients with Crohn's disease. PloS One. 2013;8(3):e60094.

83. GlaxoSmithKline. A study to investigate the efficacy and safety of GSK1605786A in the treatment of subjects with moderately-to-severely active Crohn's disease (SHIELD-1). Available from: http://clinicaltrials. gov/show/NCT01277666. NLM Identifier: NCT01277666. Accessed August 2, 2014.

84. GlaxoSmithKline. GSK1605786A in the maintenance of remission in subjects with Crohn's disease (SHIELD-2). Available from: http:// clinicaltrials.gov/show/NCT01316939. NLM Identifier: NCT01316939. Accessed August 2, 2014.

85. GlaxoSmithKline. Open-label extension study of GSK1605786A (SHIELD-3). Available from: http://clinicaltrials.gov/show/NCT01318993. NLM Identifier: NCT01318993. Accessed August 2, 2014.

86. GlaxoSmithKline. An active treatment study to induce clinical response and/or remission with GSK1605786A in subjects with Crohn's disease (SHIELD-4). Available from: http://clinicaltrials.gov/show/NCT01536418. NLM Identifier: NCT01536418. Accessed August 2, 2014.

87. Eberhardson M, Marits P, Jones M, et al. Treatment of inflammatory bowel disease by chemokine receptor-targeted leukapheresis. Clin Immunol. 2013;149(1):73-82.

88. Grant AJ, Lalor PF, Hubscher SG, Briskin M, Adams DH. MAdCAM-1 expressed in chronic inflammatory liver disease supports mucosal lymphocyte adhesion to hepatic endothelium (MAdCAM-1 in chronic inflammatory liver disease). Hepatology. 2001;33(5):1065-1072.

89. ChemoCentryx. Safety and activity study of an oral medication to treat moderate to severe Crohn's disease. Available from: http://clinicaltrials. gov/show/NCT00102921. NLM Identifier: NCT00102921. Accessed August 2, 2014.
90. Johansson C, Ahlstedt I, Furubacka S, Johnsson E, Agace WW, QuidingJärbrink M. Differential expression of chemokine receptors on human $\mathrm{IgA}^{+}$and $\mathrm{IgG}^{+} \mathrm{B}$ cells. Clin Exp Immunol. 2005;141(2):279-287.

91. Kunkel EJ, Kim CH, Lazarus NH, et al. CCR10 expression is a common feature of circulating and mucosal epithelial tissue IgA Ab-secreting cells. J Clin Invest. 2003;111(7):1001-1010.

92. Wirtz S, Neufert C, Weigmann B, Neurath MF. Chemically induced mouse models of intestinal inflammation. Nat Protoc. 2007;2(3):541-546.

93. Reuter BK, Pizarro TT. Mechanisms of tight junction dysregulation in the SAMP1/YitFc model of Crohn's disease-like ileitis. Ann NY Acad Sci. 2009;1165:301-307.

94. Apostolaki M, Manoloukos M, Roulis M, et al. Role of beta7 integrin and the chemokine/chemokine receptor pair CCL25/CCR9 in modeled TNF-dependent Crohn's disease. Gastroenterology. 2008;134(7):2025-2035.

95. Powrie F, Leach MW, Mauze S, Caddle LB, Coffman RL. Phenotypically distinct subsets of $\mathrm{CD}^{+} \mathrm{T}$ cells induce or protect from chronic intestinal inflammation in C. B-17 scid mice. Int Immunol. 1993;5(11):1461-1471.

96. Mizukami T, Kanai T, Mikami Y, et al. CCR9(+) macrophages are required for eradication of peritoneal bacterial infections and prevention of polymicrobial sepsis. Immunol Lett. 2012;147(1-2):75-79.

97. Wang C, Kang SG, Hogenesch H, Love PE, Kim CH. Retinoic acid determines the precise tissue tropism of inflammatory Th17 cells in the intestine. J Immunol. 2010;184(10):5519-5526.
Clinical and Experimental Gastroenterology

\section{Publish your work in this journal}

Clinical and Experimental Gastroenterology is an international, peerreviewed, open access journal, publishing all aspects of gastroenterology in the clinic and laboratory, including: Pathology, pathophysiology of gastrointestinal disease; Investigation and treatment of gastointestinal disease; Pharmacology of drugs used in the alimentary tract;

\section{Dovepress}

Immunology/genetics/genomics related to gastrointestinal disease. This journal is indexed on CAS. The manuscript management system is completely online and includes a very quick and fair peer-review system. Visit http://www.dovepress.com/testimonials.php to read real quotes from published authors. 